\title{
Bacterial diversity in the gastrointestinal tracts of Rhinolophus luctus and Murina leucogaster in Henan Province, China
}

\author{
Yan Sun ${ }^{1} \cdot$ Zhimin Yuan ${ }^{1} \cdot$ Yuming Guo ${ }^{2} \cdot$ Yuanzhao Qin ${ }^{2} \cdot$ Yongtian Ban $^{2} \cdot$ Hongxing Niu ${ }^{1} \cdot$ Yanzhen Bu $^{1}$
}

Received: 4 July 2019 / Accepted: 3 November 2019/Published online: 21 November 2019

(C) The Author(s) 2019

\begin{abstract}
Purpose Previous studies have assessed the diversity of gastrointestinal bacteria in bats and reported that some of the strains are pathogenic to humans; therefore, bats are considered to be potential reservoirs of zoonotic pathogens. However, the bacterial diversity and types of pathogenic bacteria in the gastrointestinal tracts of Rhinolophus luctus and Murina leucogaster have not yet been determined. Humans frequently come into contact with these species; therefore, assessments of their gut microbiota, especially potential pathogens, are essential for public health. In the present study, MiSeq high-throughput sequencing was used to address this research gap, and the results were compared with those reported previously.

Methods The V3-V4 regions of the 16S rRNA gene were sequenced using the MiSeq high-throughput sequencing platform to determine the bacterial community of the stomach and the intestines of R. luctus and M. leucogaster.

Results The bacteria in the gastrointestinal tracts of $R$. luctus and M. leucogaster were classified into three and four main bacterial phyla, respectively. In both R. luctus and M. leucogaster, the dominant phylum was Proteobacteria (stomach $86.07 \%$ and $95.79 \%$, intestines $91.87 \%$ and $88.78 \%$, respectively), followed by Firmicutes (stomach $13.84 \%$ and $4.19 \%$, intestines $8.11 \%$ and $11.20 \%$, respectively). In total, 18 and 20 bacterial genera occurred in a relative abundance of $0.01 \%$ or more in the gastrointestinal tracts of R. luctus and M. leucogaster, respectively. In R. luctus, the dominant genera were Lactococcus $(10.11 \%)$ and Paeniclostridium (3.41\%) in the stomach, and Undibacterium (28.56\%) and Paeniclostridium (4.69\%) in the intestines. In M. leucogaster, the dominant genera were Undibacterium (54.41\%) and Burkholderia (5.28\%) in the stomach, and Undibacterium (29.67\%) and Enterococcus (7.19\%) in the intestines. Among the detected gastrointestinal tract flora of R. luctus and M. leucogaster, 12 bacterial genera were pathogenic or opportunistic pathogens.

Conclusion A high number of human pathogens were detected in the gastrointestinal tracts of $R$. luctus and M. leucogaster, which demonstrates the urgency for increased efforts in the prevention and management of bat-to-human disease transmission from these species.
\end{abstract}

Keywords Rhinolophus luctus $\cdot$ Murina leucogaster $\cdot$ 16S rRNA gene $\cdot$ High-throughput sequencing $\cdot$ Pathogenic bacteria

\section{Introduction}

The microbiota in animal gastrointestinal tracts form complex communities, in which bacteria constitute a

Electronic supplementary material The online version of this article (https://doi.org/10.1007/s13213-019-01524-0) contains supplementary material, which is available to authorized users.

Yanzhen Bu

buyanzhen@htu.cn

1 College of Life Science, Henan Normal University, Xinxiang 453007, China

2 Administration Bureau of Xinxiang National Nature Reserve, Xinxiang 453000, China major part. Gastrointestinal bacteria can perform crucial functions for their hosts, including metabolic, growth and development, immune regulation, and a variety of other biological processes (Hanning and Diaz-Sanchez 2015). However, some bacterial strains are pathogenic and potentially zoonotic; and thus represent threats to human health. Accordingly, animal gastrointestinal bacterial diversity has become a highly researched topic worldwide (Yurist-Doutsch et al. 2014; Javed et al. 2017; Yuan et al. 2017). Allocati et al. (2016) reported that bats were associated with a variety of zoonoses, notably bartonellosis, leptospirosis, and pasteurellosis. Bats are known to serve as natural reservoirs for many pathogens; therefore, they represent ideal experimental animals for the study of pathogenic bacteria. 
Currently, more than 1200 different species of bats are known worldwide (Fenton and Simmons 2015). In China, there are 155 species of bats (Zhang 2010), of which 77 (49.6\%) are cave-dwelling (Wang 2003; Wang and Xie 2004). Bats are closely associated with human life, e.g., their feces are used in certain medicines or as an agricultural fertilizer, and wild-caught bats are commonly consumed in southern China. In addition, the rapid development of tourism in China in recent years has led to many bat-occupied caves being exploited as tourist attractions, which not only destroys the living environment for the bats, but also increases the risk of human contact with the bats or their feces and the potential transmission of pathogenic bacteria to humans ( $\mathrm{Bu}$ et al. 2014). Furthermore, pathogenic bacteria may also be transmitted to domestic animals and humans via bat guanocontaminated drinking water sources. Therefore, to prevent and manage the occurrence of zoonoses between bats and humans, the types of pathogenic bacteria in the gastrointestinal tract of bats urgently require elucidation.

To date, previous studies on bats have mainly focused on roost selection (Bu et al. 2015; Liu et al. 2019), echolocation (Denzinger et al. 2018), subspecies classification (Zhang et al. 2016), species diversity ( $\mathrm{Bu}$ et al. 2014), etc., with relatively fewer studies having investigated the gastrointestinal tract flora of bats (Prem Anand and Sripathi 2004; Chaverri 2006; Daniel et al. 2013; Zhou et al. 2016; Yuan et al. 2017). The methods used in most studies are limited to culturable microbial communities, and research on the gastrointestinal pathogenic bacteria of bats is still in its infancy. Due to its high accuracy, high sequencing speed, and low cost, high-throughput sequencing technology has recently and increasingly been used to detect the microbiota in the gastrointestinal tracts of bats. Using this technology, Hatta et al. (2016) found Campylobacter jejuni in the rectal microbiota of Rousettus amplexicaudatus. The results reported by Yuan (2018) indicated that the gastrointestinal tract flora of Miniopterus fuliginosus and Rhinolophus ferrumequinum harbored pathogenic bacterial genera, such as Acinetobacter, Morganella, and Mycoplasma. Until now, there have been no reports on the bacterial diversity in the gastrointestinal tracts of Rhinolophus luctus and Murina leucogaster. These species feed on insects and occur throughout a wide geographic distribution in China. Because humans frequently come into contact with these species, assessments of their gut microbiota, especially of potential pathogens, are essential for public health.

The present study, therefore, determined the bacterial diversity and the types of pathogenic bacteria in the gastrointestinal tracts of $R$. luctus and M. leucogaster, using MiSeq highthroughput sequencing technology. The results of this study were then compared with other published reports. The major aim of this study was to provide basic reference information for future research of pathogenic bacteria in bats, and for management departments to formulate scientific and reasonable strategies for the development and protection of caves inhabited by bats to reduce the occurrence of zoonosis.

\section{Materials and methods}

\section{Sample collection and processing}

All samples were collected in June 2018. Three female $R$. luctus adults were collected using mist nets in Donggangou Cave, Luoyang City, Henan Province, China (N 33 53' 41.28", E $\left.112^{\circ} 06^{\prime} 46.44^{\prime \prime}\right)$. Three adult M. leucogaster (two males and one female) were captured from Laoyindong Cave in Luoyang City, Henan Province, China (N $33^{\circ} 55^{\prime} 47.64^{\prime \prime}$, E $112^{\circ} 05^{\prime} 26.52^{\prime \prime}$ ). The bat species were identified using A Guide to the Mammals of China (Smith and Xie 2009). The bats were transported alive to a laboratory and starved for $24 \mathrm{~h}$ prior to euthanasia.

An overdose of chloroform was used to euthanize the bats. The bats were immersed in $70 \%$ ethanol for surface disinfection and then rinsed with sterile water. The stomach and the entire intestinal contents were separately removed using sterile surgical forceps and a scalpel under aseptic conditions. The stomach contents of $R$. luctus (DW1, DW2, DW3), intestinal contents of $R$. luctus (DC1, DC2, DC3), stomach contents of M. leucogaster (BW1, BW2, BW3), and intestinal contents of M. leucogaster (BC1, BC2, BC3) were placed in separate 5$\mathrm{ml}$ sterile centrifuge tubes.

\section{DNA extraction, PCR amplification, and MiSeq sequencing}

The total genomic DNA was extracted from the stomach and intestinal contents of each sample using the Stool DNA Kit (Feiyang, Guangzhou, China) according to the manufacturer's instructions. The V3-V4 regions of the bacterial 16S rRNA gene (from genomic DNA) were amplified using the followi n g p rim e r s : V $3 \sim \mathrm{V} 4 \mathrm{~F}: 5^{\prime}-\mathrm{C}$ C T A CGGRRBGCASCAGKVRVGAAT-3'; V3 V4 R: 5'-GGAC TACNVGGGTWTCTAATCC-3'. The polymerase chain reactions (PCRs) were performed in a $20-\mu \mathrm{l}$ reaction system under the following conditions for 24 cycles: $94{ }^{\circ} \mathrm{C}$ for 3 min; $94{ }^{\circ} \mathrm{C}$ for $5 \mathrm{~s} ; 57^{\circ} \mathrm{C}$ for $90 \mathrm{~s} ; 72^{\circ} \mathrm{C}$ for $10 \mathrm{~s}$, and a final elongation at $72{ }^{\circ} \mathrm{C}$ for $5 \mathrm{~min}$. The PCR amplification products were sequenced using the Illumina MiSeq 300 PE system (GENEWIZ, Suzhou, China).

\section{Data analysis}

Quality filtering was conducted on the original sequences. Effective sequences used in the clustering analysis were obtained by removing the chimeric sequences. Each cluster was treated as an operational taxonomic unit (OTU). Sequences 
were grouped into OTUs based on 97\% sequence identity using the clustering program VSEARCH (1.9.6). The Ribosomal Database Program (RDP) classifier was used to assign taxonomic categories to all OTUs. Analyses were conducted using Qiime v.1.9.1 to reveal the Alpha diversity of the stomach and intestinal samples, including the Chaol abundance index, Shannon diversity index, and coverage index. The Beta diversity was calculated using the principal coordinates analysis (PCoA). The community structure of the samples was then statistically analyzed at the phylum and genus levels based on the taxonomic data.

\section{Results}

\section{Gastrointestinal tract flora composition and alpha diversity}

An average of 74,615 and 74,424 original sequences, as well as 53,576 and 53,533 effective sequences, were obtained from the stomach and intestine samples of the R. luctus specimens $(n=3)$. The effective sequences were clustered into 28 OTUs, respectively. An average of 81,121 and 77,242 original sequences, as well as 57,440 and 55,598 effective sequences, which were assigned to 36 and 40 OTUs, were obtained from the stomach and intestine samples of the M. leucogaster specimens $(n=3)$ (Table 1$)$. In addition, the gastrointestinal tract flora of $R$. luctus and $M$. leucogaster contained 46 nonrepetitive OTUs, of which $19(41.3 \%)$ were shared by four sample groups; indicating a certain similarity in the composition of the gastrointestinal flora of R. luctus and M. leucogaster (Fig. 1).

The rarefaction curves of the 12 samples eventually tended to level out, which indicated that the sequencing depth and breadth of the samples met the requirements (Fig. 2).
Moreover, the Good's coverage rate of each sample was $100 \%$, which indicated that the samples sufficiently represented the bacterial diversity in the gastrointestinal tract of the study species. The gastrointestinal bacterial abundance and diversity were higher in the intestines than in the stomach of $R$. luctus. In contrast, the abundance and diversity were lower in the intestines than in the stomach of M. leucogaster. The Chaol abundance index and Shannon diversity index of the gastrointestinal flora of these two bat species are presented in Table 1.

\section{Beta diversity analysis}

The PCoA plot, based on the Bray-Curtis distance matrices, revealed the similarities and differences of the bacterial gastrointestinal communities among samples (Fig. 3). Samples from the stomach and intestinal flora of R. luctus were clustered together and distributed on the right side of the 0 point. In contrast, the samples of the gastrointestinal flora of M. leucogaster were scattered on the left side of the 0 point. $\mathrm{PCoA}$ analysis indicated that there were differences in the bacterial composition of the gastrointestinal tracts of R. luctus and M. leucogaster.

\section{Microbial community structure at phylum level}

The bacteria in the gastrointestinal tract of $R$. luctus were from three phyla: Proteobacteria, Firmicutes, and Bacteroidetes. The most abundant phylum was Proteobacteria (stomach $86.07 \%$, intestines $91.87 \%$ ), followed by Firmicutes (stomach $13.84 \%$, intestines $8.11 \%$ ), and the least represented phylum was Bacteroidetes (only intestines $0.02 \%$ ). The bacteria in the gastrointestinal tract of $M$. leucogaster were mainly from four phyla: Proteobacteria, Firmicutes, Bacteroidetes, and Actinobacteria. The most abundant phylum was
Table 1 Number of sequences and alpha diversity of gastrointestinal bacteria in the stomach and intestines of Rhinolophus luctus and Murina leucogaster

\begin{tabular}{|c|c|c|c|c|c|c|}
\hline $\begin{array}{l}\text { Sample } \\
\text { name }\end{array}$ & $\begin{array}{l}\text { Original } \\
\text { sequences }\end{array}$ & $\begin{array}{l}\text { Effective } \\
\text { sequences }\end{array}$ & $\begin{array}{l}\text { No. of } \\
\text { OTUs }\end{array}$ & $\begin{array}{l}\text { Chaol } \\
\text { index }\end{array}$ & $\begin{array}{l}\text { Shannon } \\
\text { index }\end{array}$ & $\begin{array}{l}\text { Good's } \\
\text { coverage (\%) }\end{array}$ \\
\hline $\mathrm{DW}^{\mathrm{c}}$ & 74,615 & 53,576 & 28 & $\begin{array}{c}25.00 \pm \\
1.32\end{array}$ & $1.62 \pm 0.10$ & 1 \\
\hline$D C^{d}$ & 74,424 & 53,533 & 28 & $\begin{array}{c}25.78 \pm \\
1.68\end{array}$ & $2.59 \pm 0.03$ & 1 \\
\hline $\mathrm{BW}^{\mathrm{e}}$ & 81,121 & 57,440 & 36 & $\begin{array}{c}30.75 \pm \\
4.38\end{array}$ & $2.40 \pm 0.47$ & 1 \\
\hline$B C^{f}$ & 77,242 & 55,598 & 40 & $\begin{array}{c}30.25 \pm \\
7.13\end{array}$ & $1.76 \pm 0.39$ & 1 \\
\hline
\end{tabular}

\footnotetext{
${ }^{\text {a }}$ Number of operational taxonomic units (OTUs)

${ }^{\mathrm{b}}$ The values indicate means \pm standard errors $(n=3)$

${ }^{\mathrm{c}}$ The stomach contents of $R$. luctus

${ }^{\mathrm{d}}$ The intestinal contents of $R$. luctus

${ }^{\mathrm{e}}$ The stomach contents of M. leucogaster

${ }^{\mathrm{f}}$ The intestinal contents of $M$. leucogaster
} 


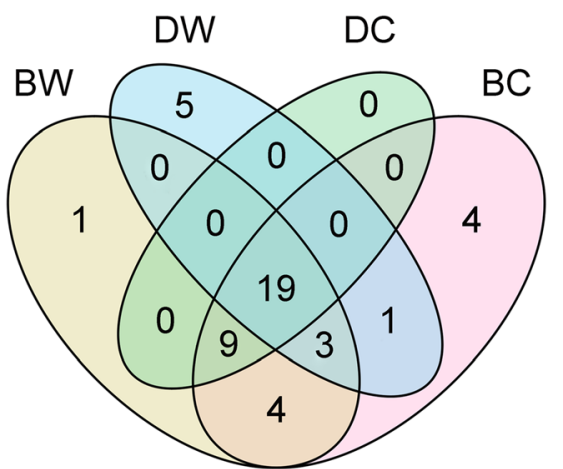

Fig. 1 Venn diagram of the stomach and intestinal contents of Rhinolophus luctus (DW and DC, respectively) and the stomach and intestinal contents of Murina leucogaster (BW and BC, respectively)

Proteobacteria (stomach 95.79\%, intestines 88.78\%), followed by Firmicutes (stomach $4.19 \%$, intestines $11.20 \%$ ), and Bacteroidetes (stomach $0.02 \%$, intestines $0.01 \%$ ), and the least represented phylum was Actinobacteria (only intestines $0.01 \%$ ) (Fig. 4 and Table S1 in Supplementary Materials).

\section{Microbial community structure at genus level}

The genera with relative abundances higher than $0.01 \%$ in the gastrointestinal tracts of $R$. luctus and M. leucogaster are presented in a genus-level high-throughput heat map (Fig. 5). The shades of color in the heat map represent the abundance of each genus in the samples. Undibacterium, Lactococcus, Burkholderia, Enterococcus, and Paeniclostridium were found to be abundant in each sample (Fig. 5 and Fig. 6). Overall, 18 and 20 bacterial genera occurred in relative abundances higher than $0.01 \%$ in the gastrointestinal tracts of R. luctus and M. leucogaster, respectively. Rhinolophus luctus and M. leucogaster shared

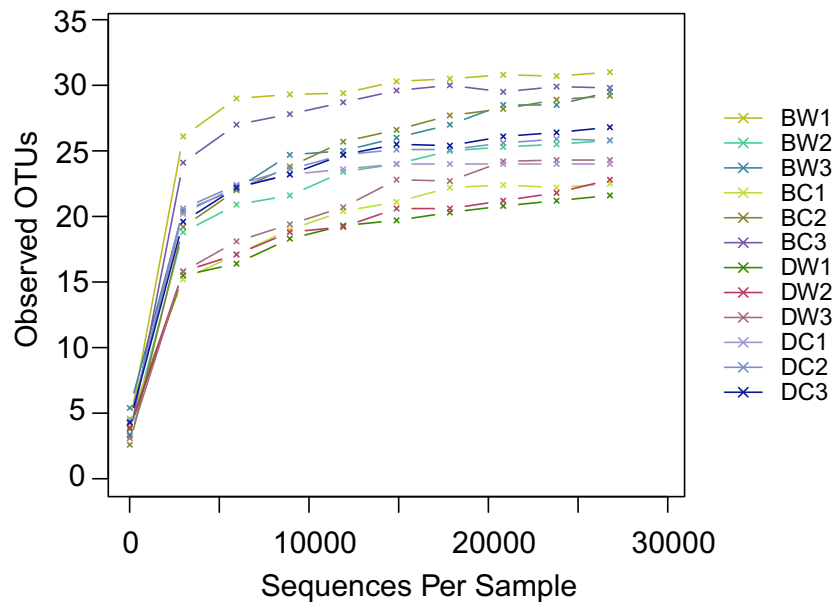

Fig. 2 Rarefaction curves of the observed operational taxonomic units (OTUs) in the stomach contents of Rhinolophus luctus (DW1, DW2, DW3), the intestinal contents of $R$. luctus (DC1, DC2, DC3), the stomach contents of Murina leucogaster (BW1, BW2, BW3), and the intestinal contents of M. leucogaster (BC1, BC2, BC3)

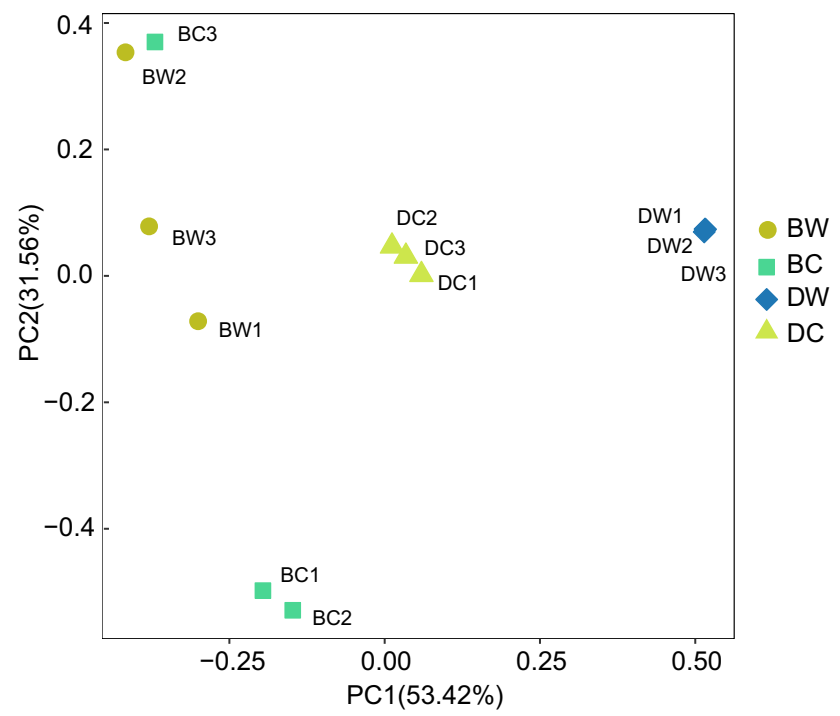

Fig. 3 PCoA plot showing the similarities and differences of the bacterial gastrointestinal communities of Rhinolophus luctus and Murina leucogaster

18 bacterial genera (Undibacterium, Lactococcus, Burkholderia, Enterococcus, Paeniclostridium, Citrobacter, Staphylococcus, Actinobacillus, Clostridium_sensu_stricto_1, Acinetobacter, Pseudomonas, Escherichia/Shigella, Caulobacter, Sphingomonas, Novosphingobium, Acetobacter, Pseudarcicella, Blautia). Two unique bacterial genera, i.e., Collinsella and Turicibacter, were obtained from the intestines of M. leucogaster. The color differences in the heat map indicate the differences in the abundance and dominance of bacteria in the gastrointestinal tracts of R. luctus and M. leucogaster. In R. luctus, the dominant genera in the stomach were Lactococcus (relative

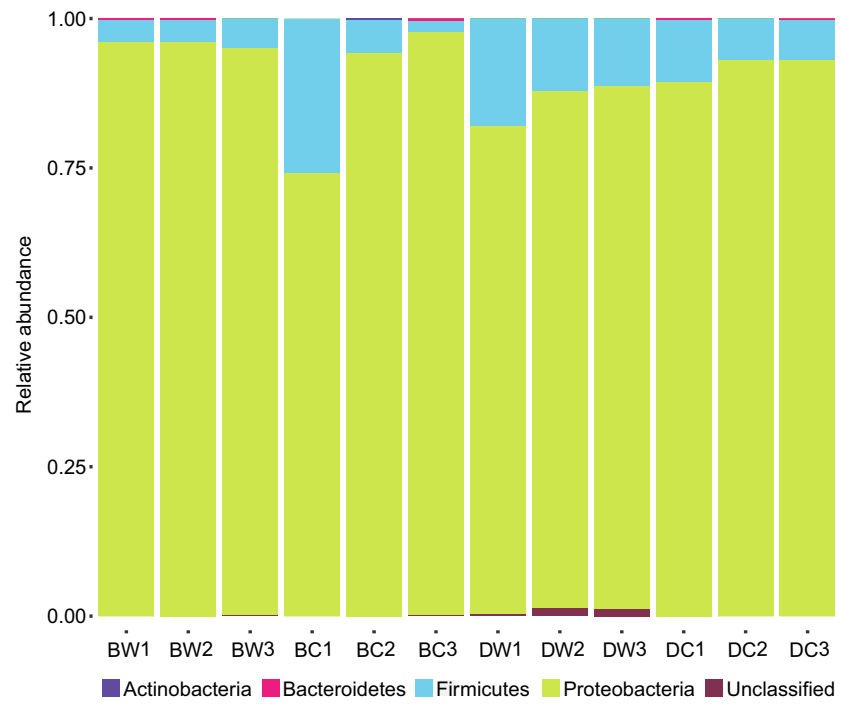

Fig. 4 The phylum-level community abundance of bacterial microbiota in different gastrointestinal samples of Rhinolophus luctus and Murina leucogaster 
Fig. 5 A genus-level taxonomic heat map of the gastrointestinal bacterial compositions of Rhinolophus luctus and Murina leucogaster

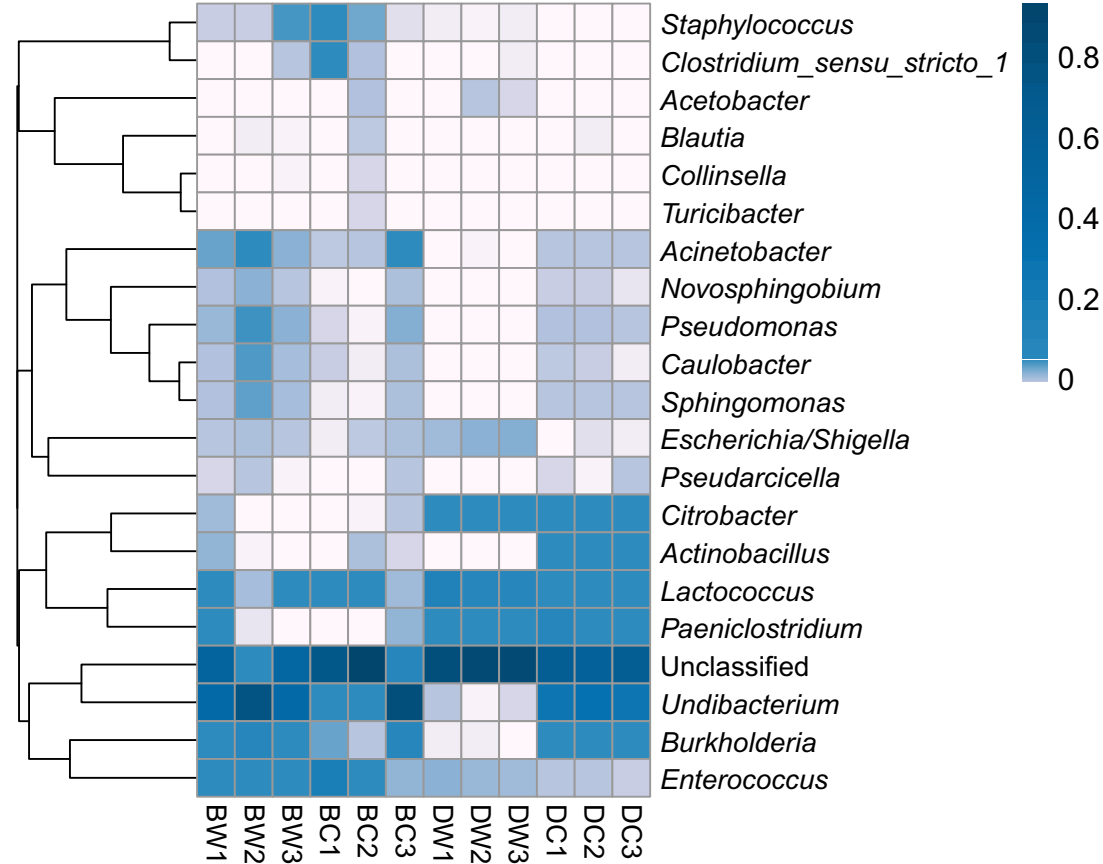

abundance $10.11 \%$ ) and Paeniclostridium (3.41\%), and the dominant genera in the intestines were Undibacterium (28.56\%) and Paeniclostridium (4.69\%). In $M$. leucogaster, the dominant genera in the stomach were Undibacterium (54.41\%) and Burkholderia $(5.28 \%)$, and the dominant genera in the intestines were Undibacterium (29.67\%) and Enterococcus (7.19\%) (Fig. 5, Fig. 6, and Table S2 in Supplementary Materials). Furthermore, the sequences that could not be classified into any known genus were assigned as "unclassified."

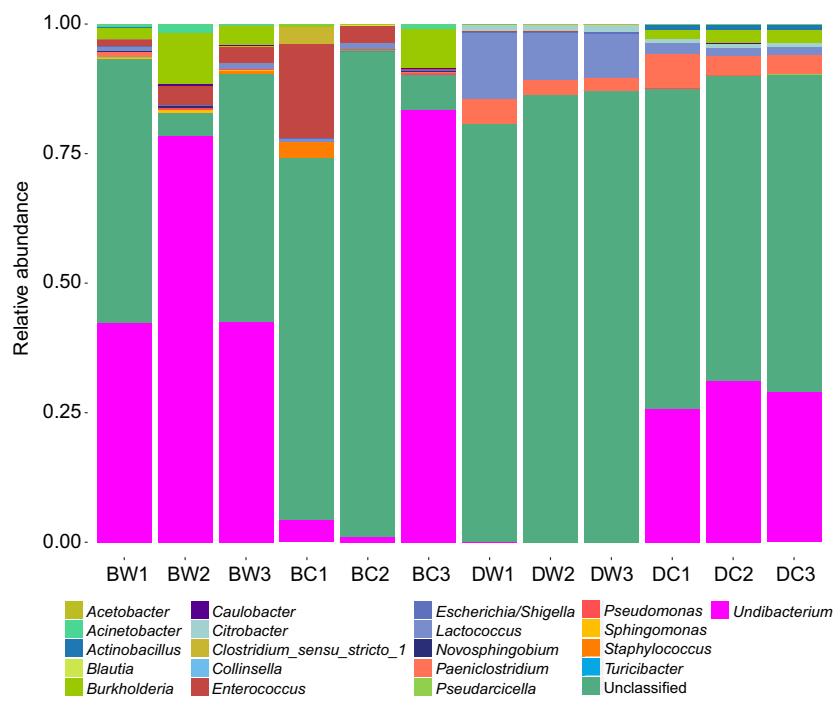

Fig. 6 The genus-level community abundance of bacterial microbiota in different gastrointestinal samples of Rhinolophus luctus and Murina leucogaster
Some unclassified genera were detected in the gastrointestinal tracts of both $R$. luctus and M. leucogaster.

\section{Discussion}

MiSeq high-throughput sequencing technology has previously been used to study bacterial diversity in the gastrointestinal tracts of bats (Zhou 2016; Yuan 2018; Wu et al. 2019). The abundance and diversity of the intestinal flora of Hipposideros pratti, Hypsugo alaschanicus, M. fuliginosus, and $R$. ferrumequinum were found to be higher than those of the stomach flora (Zhou 2016; Yuan 2018), which is consistent with the findings of $R$. luctus in the present study. In contrast, the abundance and diversity of the intestinal flora of $M$. leucogaster were found to be lower than the stomach flora (Table 1). A recent study on the gastrointestinal flora of C57BL/6 mice demonstrated the existence of a "transient microbiota" from prey species, which resulted in the relatively high diversity in the stomach (Gu et al. 2013). Differences in the bacterial abundance and diversity of the gastrointestinal tract flora of $M$. leucogaster and R. luctus, H. pratti, $H$. alaschanicus, $M$. fuliginosus, and $R$. ferrumequinum may be related to food intake or bacterial specificity (CarrilloAraujo et al. 2015). However, further research is needed to confirm the gastrointestinal bacterial compositions of more bat species to reveal differences among species and to clarify such relations.

PCoA clearly revealed differences in the bacterial compositions of the gastrointestinal tracts of $R$. luctus and M. leucogaster (Fig. 3). Flora samples from the 
gastrointestinal tracts of $R$. luctus were clustered together, which indicated that the gastrointestinal bacterial communities were comparatively similar. The samples of the gastrointestinal flora of $M$. leucogaster showed higher variations.

The dominant bacterial phyla in the gastrointestinal tracts of the different bat species were found to be inconsistent; however, major similarities were evident among some bat species. The most dominant phylum in the gastrointestinal tracts of R. luctus and M. leucogaster was Proteobacteria (i.e., $86.07 \%$ and $95.79 \%$ in the stomach, and $91.87 \%$ and $88.78 \%$ in the intestines, respectively) (Fig. 4 and Table S1 in Supplementary Materials), which was consistent with the findings of Yuan (2018) and Wu et al. (2019). Proteobacteria was the predominant phylum in the gastrointestinal tract of R. ferrumequinum (i.e., $80.25 \%$ in the stomach and $74.12 \%$ in the intestines) (Yuan 2018) and in the intestines of Rhinolophus sinicus and Myotis altarium (i.e., $43.5 \%$ and $42.5 \%$, respectively) (Wu et al. 2019). The bacterial diversity of the gastrointestinal tract flora in bats may be closely related to their habitat and associated environmental factors. Globally, Proteobacteria is the dominant taxa found on cave walls (Pasic et al. 2010; Wu et al. 2015). Rhinolophus luctus, $M$. leucogaster, $R$. ferrumequinum, $R$. sinicus, and $M$. altarium are all cave-dwelling bats, which may account for the dominance of Proteobacteria in their gastrointestinal bacterial microbiota.

Firmicutes was the second most predominant phylum in the gastrointestinal tracts of $R$. luctus and M. leucogaster (i.e., $13.84 \%$ and $4.19 \%$ in the stomach, and $8.11 \%$ and $11.20 \%$ in the intestines, respectively) (Fig. 4 and Table S1 in Supplementary Materials). However, Firmicutes was the predominant bacterial phylum in the intestines of $M$. fuliginosus and in the stomach of $H$. alaschanicus, accounting for 55.78\% and $59.5 \%$ of the relative abundance, respectively (Yuan 2018; Zhou 2016). A study of the rectal microbiota in $R$. amplexicaudatus from the Philippines also reported the predominance of Firmicutes (Hatta et al. 2016). Firmicutes has been found to be a universally shared phylum in mammals (Ley et al. 2008). For example, the relative abundance of Firmicutes in the intestinal flora of Namibian cheetahs (Acinonyx jubatus) (Wasimuddin et al. 2017) and humans (Tap et al. 2009) is reportedly $68.5 \%$ and $79.4 \%$, respectively. Members of the phylum Firmicutes are involved in the decomposition of complex carbohydrates and fatty acids, and thus provide nutrition and energy for all animal hosts (Flint et al. 2008). Therefore, the presence of a large number of Firmicutes may contribute to the digestion of available food resources in bats.

At the genus level, the dominant genus in the stomach and intestines of R. luctus were Lactococcus (10.11\%) and Undibacterium (28.56\%), respectively. Six genera in the gastrointestinal tract flora of $R$. luctus had relative abundances of $1 \%$ or more. The dominant genus in the gastrointestinal tract of M. leucogaster was Undibacterium (54.41\% and 29.67\%).
Five genera in the gastrointestinal tract flora of M. leucogaster had relative abundances greater than 1\% (Fig. 6 and Table S2 in Supplementary Materials). Comparisons of the findings of previous studies revealed similarities and differences in the dominant bacterial genera in the stomach and intestines of different bat species. The dominant genera were found to mainly include Undibacterium, Lactococcus, Enterococcus, Actinobacillus, and Sphingomonas. The genera with relative abundances of more than $1 \%$ were also inconsistent (Table S2 in Supplementary Materials), which might be related to differences in habitats and associated environmental factors (Carrillo-Araujo et al. 2015). Under different environmental conditions, bacteria specific to the different conditions may accumulate in the intestines and thus alter the gut microbial communities of wild animals (Wu et al. 2018). Rhinolophus luctus, M. leucogaster, H. pratti, and R. ferrumequinum mainly live in natural caves and abandoned mines. Miniopterus fuliginosus and $H$. alaschanicus are house-dwelling bats, which mainly inhabit abandoned buildings in humanassociated areas. These differences in roosting locations may account for the observed differences in the composition and dominance of the gastrointestinal bacteria.

Recent studies have shown diet to be the major determinant of gut microbial composition (Moschen et al. 2012). For example, dietary factors were demonstrated to play a dominant role in altering the gut microbiota of the bar-headed goose (Anser indicus) (Wang et al. 2016), green turtles (Chelonia mydas) (Ahasan et al. 2018), and humans (Makki et al. 2018). Bats are mainly divided into phytophagous and insectivorous species based on their diets (Li et al. 2018), and R. luctus and $M$. leucogaster are classified as insectivorous bats. In the present study, Citrobacter was identified in the gastrointestinal tracts of these species and was also detected in the gastrointestinal tracts of nine insectivorous bats in Indiana (Whitaker et al. 2004). Chitinase, produced by the bacteria from the Citrobacter genus, aids in the digestion of the remnants of chitin from insects and thus provides energy and nutrients to these bats. Rousettus amplexicaudatus from the Philippines is a frugivorous bat. Serratia isolated from the rectal microbiota of this species possesses the ability to break down cellulose and xylan, the main components of plants, and thus supply energy to these bats (Prem Anand and Sripathi 2004; Hatta et al. 2016). The gastrointestinal tract flora of $R$. luctus and M. leucogaster shared two genera with relative abundances of more than $1 \%$; however, no common genera were observed in the gastrointestinal tract flora of $R$. amplexicaudatus, $R$. luctus, and M. leucogaster (Table S2 in Supplementary Materials). The compositions of the gastrointestinal tract flora of the insectivorous bats, R. luctus and M. leucogaster, were similar and also shared two genera. The composition of the gastrointestinal tract flora of $R$. amplexicaudatus, a frugivorous bat, differed greatly from that of R. luctus and M. leucogaster. The bacterial communities showed specific associations with diet (e.g., 
insectivory and frugivory); thus, our findings confirmed diet to be one of the factors that affect the composition of the gastrointestinal flora of bats.

The gastrointestinal flora of $R$. luctus and M. leucogaster contained 18 and 20 bacterial genera, respectively, of which 12 genera (Lactococcus, Burkholderia, Enterococcus, Paeniclostridium, Citrobacter, Staphylococcus, Actinobacillus, Clostridium_sensu_stricto_1, Acinetobacter, Pseudomonas, Escherichia/Shigella, Sphingomonas) were pathogenic bacteria or opportunistic pathogens (Goldman and Green 2008). Some bacteria of the genus Lactococcus are responsible for various infectious diseases in humans, including osteomyelitis, endocarditis, and sepsis ( $\mathrm{Li}$ et al. 2005). Although members of Enterococcus have been reported as normal gut inhabitants of humans and animals, these bacteria are well known to cause opportunistic infections, such as meningitis, endocarditis, and bacteremia (Wei 2018). Some members of the genus Citrobacter are important pathogens in human respiratory, urinary, and surgical wound infections (Wei et al. 2016). Among these pathogens, Citrobacter freundii is an opportunistic pathogen that causes neonatal infections, which can lead to sepsis and meningitis with a high mortality rate (Holmes and Aucken 1998). Lactococcus, Enterococcus, and Citrobacter were detected in Rousettus leschenaultii guano (Banskar et al. 2016) and the gastrointestinal tract of $H$. pratti and H. alaschanicus (Zhou 2016). In recent years, caves especially occupied by bats, have been developed into tourist attractions, which has increased the chance of human contact with bats and the possibility of human infection with pathogenic bacteria. Thus, further studies are needed to ascertain the transmission routes of pathogenic bacteria carried by bats.

To avoid the occurrence of zoonosis, management departments are urged to adopt scientific and rational methods to create, develop, or restrict access to caves inhabited by bats, to reduce or effectively control opportunities for human-bat interactions. The present study provides reference information on which such efforts and other studies can be based.

Acknowledgments We thank Liumeng Zheng and Jie Wu for their help with the sample collection and necessary information. We would also like to thank Guojun Zhang, Yingying Liu, Junlou Li, Lili Hu, Wenchang Zhang, Deqi Geng, Yilin Wang, and Min Zhang for the field assistance during bat sampling.

Author contributions All authors contributed to the study conception and design. Material preparation, data collection, and analysis were performed by Zhimin Yuan, Yuming Guo, Yongtian Ban, and Yuanzhao Qin. The first draft of the manuscript was written by Yan Sun. The manuscript was revised by Yanzhen $\mathrm{Bu}$ and Hongxing Niu. All authors commented on previous versions of the manuscript. All authors read and approved the final manuscript.

Funding information This project was supported by the National Natural Science Foundation of China (NSFC, No. U1704102) and Bird Research Project of Administration Bureau of Xinxiang National Nature Reserve (No. 5201049160034).

\section{Compliance with ethical standards}

Conflict of interest The authors declare that they have no conflict of interest.

Research involving human participants and/or animals All fieldwork was conducted in accordance with the Law of the People's Republic of China on the Protection of Wildlife. All experiments on living bats followed the American Society of Mammalogists guidelines for the use of wild mammals in research.

Informed consent Not applicable.

Open Access This article is distributed under the terms of the Creative Commons Attribution 4.0 International License (http:// creativecommons.org/licenses/by/4.0/), which permits unrestricted use, distribution, and reproduction in any medium, provided you give appropriate credit to the original author(s) and the source, provide a link to the Creative Commons license, and indicate if changes were made.

\section{References}

Ahasan MS, Waltzek TB, Huerlimann R, Ariel E (2018) Comparative analysis of gut bacterial communities of green turtles (Chelonia mydas) pre-hospitalization and post-rehabilitation by highthroughput sequencing of bacterial 16S rRNA gene. Microbiol Res 207:91-99. https://doi.org/10.1016/j.micres.2017.11.010

Allocati N, Petrucci AG, Di Giovanni P, Masulli M, Di Ilio C, De Laurenzi V (2016) Bat-man disease transmission: zoonotic pathogens from wildlife reservoirs to human populations. Cell Death Discov 2:16048. https://doi.org/10.1038/cddiscovery.2016.48

Banskar S, Bhute SS, Suryavanshi MV, Punekar S, Shouche YS (2016) Microbiome analysis reveals the abundance of bacterial pathogens in Rousettus leschenaultii guano. Sci Rep 6:36948. https://doi.org/ 10.1038/srep36948

Bu YZ, Wang YM, Liu W, Yu Y, He XP, Peng T, Niu HX (2014) Diversity and conservation of cave-dwelling bats in Henan Province, China. Acta Theriol Sin 34(3):252-261 (In Chinese). https://doi.org/10.16829/j.slxb.2014.03.007

Bu YZ, Wang YM, Zhang C, Liu W, Zhong HX, Yu Y, Niu HX (2015) Geographical distribution, roost selection, and conservation state of cave-dwelling bats in China. Mammalia 79(4):409-417. https://doi. org/10.1515/mammalia-2014-0008

Carrillo-Araujo M, Tas N, Alcantara-Hernandez RJ, Gaona O, Schondube JE, Medellin RA, Jansson JK, Falcon LI (2015) Phyllostomid bat microbiome composition is associated to host phylogeny and feeding strategies. Front Microbiol 6:447. https://doi. org/10.3389/fmicb.2015.00447

Chaverri G (2006) Aerobic bacterial flora from the digestive tract of the common vampire bat, Desmodus rotundus (Chiroptera: Phyllostomidae). Rev Biol Trop 54(3):717-724 (In Spanish) ISSN: 0034-7744

Daniel DS, Ng YK, Chua EL, Arumugam Y, Wong WL, Kumaran JV (2013) Isolation and identification of gastrointestinal microbiota from the shortnosed fruit bat Cynopterus brachyotis brachyotis. Microbiol Res 168(8):485-496. https://doi.org/10.1016/j.micres.2013.04.001

Denzinger A, Tschapka M, Schnitzler HU (2018) The role of echolocation strategies for niche differentiation in bats. Can J Zool 96(3): 171-181. https://doi.org/10.1139/cjz-2017-0161

Fenton MB, Simmons NB (2015) Bats: a world of science and mystery. The University of Chicago Press, Chicago.

Flint HJ, Bayer EA, Rincon MT, Lamed R, White BA (2008) Polysaccharide utilization by gut bacteria: potential for new insights 
from genomic analysis. Nat Rev Microbiol 6(2):121-131. https:// doi.org/10.1038/nrmicro 1817

Goldman E, Green LH (2008) Practical handbook of microbiology. Lewis Publishers (CRC), Boca Raton

Gu SH, Chen DD, Zhang JN, Lv XM, Wang K, Duan LP, Nie Y, Wu XL (2013) Bacterial community mapping of the mouse gastrointestinal tract. PloS ONE 8(10):e74957. https://doi.org/10.1371/journal. pone. 0074957

Hanning I, Diaz-Sanchez S (2015) The functionality of the gastrointestinal microbiome in non-human animals. Microbiome 3:51. https:// doi.org/10.1186/s40168-015-0113-6

Hatta Y, Omatsu T, Tsuchiaka S, Katayama Y, Taniguchi S, Masangkay JS, Puentespina R, Eres E, Cosico E, Une Y, Yoshikawa Y, Maeda K, Kyuwa S, Mizutani T (2016) Detection of Campylobacter jejuni in rectal swab samples from Rousettus amplexicaudatus in the Philippines. J Vet Med Sci 78(8):1347-1350. https://doi.org/10.1292/jvms.15-0621

Holmes B, Aucken H (1998) In Topley and Wilson's microbiology and microbial infections (eds Balows A and Duerden B). Arnold, London, pp 999-1033

Javed S, Gul F, Javed K, Bokhari H (2017) Helicobacter pullorum: an emerging zoonotic pathogen. Front Microbiol 8:604. https://doi.org/ $10.3389 /$ fmicb.2017.00604

Ley RE, Hamady M, Lozupone C, Turnbaugh PJ, Ramey RR, Bircher JS, Schlegel ML, Tucker TA, Schrenzel MD, Knight R, Gordon JI (2008) Evolution of mammals and their gut microbes. Science 320(5883):1647-1651. https://doi.org/10.1126/science.1155725

Li ZX, Zhang XH, Wang YX (2005) Research advance in Lactococcus and its infection. Sect Clin Biochem Lab Med Foreign Med Sci 26(12):928-931 935 (In Chinese)

Li J, Li LM, Jiang HY, Yuan LH, Zhang LB, Ma JE, Zhang XJ, Cheng MH, Chen JP (2018) Fecal Bacteriome and Mycobiome in bats with diverse diets in South China. Curr Microbiol 75(10):1352-1361. https://doi.org/10.1007/s00284-018-1530-0

Liu YY, Wang YM, Zhang ZX, Bu YZ, Niu HX (2019) Roost selection and ecology of Stoliczka's trident bat, Aselliscus stoliczkanus (Hipposideridae, Chiroptera) in China. Mamm Biol 95:143-149. https://doi.org/10.1016/j.mambio.2018.09.002

Makki K, Deehan EC, Walter J, Backhed F (2018) The impact of dietary fiber on gut microbiota in host health and disease. Cell Host Microbe 23(6):705-715. https://doi.org/10.1016/j.chom.2018.05.012

Moschen AR, Wieser V, Tilg H (2012) Dietary factors: major regulators of the gut's microbiota. Gut Liver 6(4):411-416. https://doi.org/10. 5009/gnl.2012.6.4.411

Pasic L, Kovce B, Sket B, Herzog-Velikonja B (2010) Diversity of microbial communities colonizing the walls of a Karstic cave in Slovenia. FEMS Microbiol Ecol 71(1):50-60. https://doi.org/10. 1111/j.1574-6941.2009.00789.x

Prem Anand AA, Sripathi K (2004) Digestion of cellulose and xylan by symbiotic bacteria in the intestine of the Indian flying fox (Pteropus giganteus). Comp Biochem Physiol A Mol Integr Physiol 139(1): 65-69. https://doi.org/10.1016/j.cbpb.2004.07.006

Smith AT, Xie Y (2009) A guide to the mammals of China. Hunan Education Press, Changsha (In Chinese)

Tap J, Mondot S, Levenez F, Pelletier E, Caron C, Furet JP, Ugarte E, Munoz-Tamayo R, Paslier DLE, Nalin R, Dore J, Leclerc M (2009) Towards the human intestinal microbiota phylogenetic core. Environ Microbiol 11(10):2574-2584. https://doi.org/10.1111/j. 1462-2920.2009.01982.x

Wang YX (2003) A complete checklist of mammal species and subspecies in China: a taxonomic and geographic reference. China Forestry Publishing House, Beijing (In Chinese)

Wang S, Xie Y (2004) China species red list. Higher Education Press, Beijing (In Chinese)
Wang W, Cao J, Li JR, Yang F, Li Z, Li LX (2016) Comparative analysis of the gastrointestinal microbial communities of bar-headed goose (Anser indicus) in different breeding patterns by high-throughput sequencing. Microbiol Res 182:59-67. https://doi.org/10.1016/j. micres.2015.10.003

Wasimuddin MS, Melzheimer J, Thalwitzer S, Heinrich S, Wachter B, Sommer S (2017) Gut microbiomes of free-ranging and captive Namibian cheetahs: diversity, putative functions and occurrence of potential pathogens. Mol Ecol 26(20):5515-5527. https://doi.org/ $10.1111 / \mathrm{mec} .14278$

Wei F (2018) Analysis on characteristics of Enterococcus nosocomial infection and its resistance to new antimicrobial agents. Anti Infect Pharm 15(2):209-212 (In Chinese). https://doi.org/10.13493/j.issn. 1672-7878.2018.02-007

Wei HS, Ma CH, Li LM, Li HM (2016) Clinical distribution and antimicrobial resistance of Citrobacter species in a primary hospital. Chin J Health Lab Tec 26(17):2564-2566 (In Chinese)

Whitaker JO Jr, Dannelly HK, Prentice DA (2004) Chitinase in insectivorous bats. J Mammal 85(1):15-18.https://doi.org/10.1644/15451542(2004)085<0015:CIIB >2.0.CO;2

Wu YC, Tan LC, Liu WX, Wang BZ, Wang JJ, Cai YJ, Lin XG (2015) Profiling bacterial diversity in a limestone cave of the western Loess Plateau of China. Front Microbiol 6:244. https://doi.org/10.3389/ fmicb.2015.00244

Wu YN, Yang YZ, Cao L, Yin HQ, Xu MY, Wang ZJ, Liu YY, Wang X, Deng Y (2018) Habitat environments impacted the gut microbiome of long-distance migratory swan geese but central species conserved. Sci Rep 8:13314. https://doi.org/10.1038/s41598-01831731-9

Wu HN, Xing YT, Sun HJ, Mao XG (2019) Gut microbial diversity in two insectivorous bats: insights into the effect of different sampling sources. MicrobiologyOpen 8(4):e670. https://doi.org/10.1002/ mbo3.670

Yuan ZM (2018) Study of the bacteria diversity in the gastrointestinal tract of Miniopterus fuliginosus and Rhinolophus ferrumequinum. Dissertation, Henan Normal University (In Chinese)

Yuan ZM, Wang YM, Zheng LM, Wu J, Li JL, Hu LL, Niu HX (2017) Isolation and identification of gastrointestinal bacteria from Hipposideros pratti. Prog Vet Med 38(7):105-111 (In Chinese). https://doi.org/10.16437/j.cnki.1007-5038.2017.07.023

Yurist-Doutsch S, Arrieta MC, Vogt SL, Finlay BB (2014) Gastrointestinal microbiota-mediated control of enteric pathogens. Annu Rev Genet 48:361-382. https://doi.org/10.1146/annurevgenet-120213-092421

Zhang JS (2010) The bats (Mammalia: Chiroptera) of China: an integrative approach to the taxonomy. Dissertation, Graduate University of the Chinese Academy of Sciences (In Chinese)

Zhang ZX, Wang YM, Zheng LM, Wu J, Zhao YF, Bu YZ, Niu HX (2016) Variation in Aselliscus stoliczkanus based on morphology and molecular sequence data, with a new record of the genus Aselliscus in China. J Mammal 97(6):1718-1727. https://doi.org/ 10.1093/jmammal/gyw138

Zhou HX (2016) The study of the bacterial diversity in the gastrointestinal tract of Hipposideros pratti and Hypsugo alaschanicus. Dissertation, Henan Normal University (In Chinese)

Zhou HX, Wang YM, Zhang ZX, Zhou HW, Zhao YF, Niu HX (2016) Microbial diversity in the gastrointestinal tract of Hipposideros pratti. Microbiol China 43(8):1739-1745 (In Chinese). https://doi. org/10.13344/j.microbiol.china. 150654

Publisher's note Springer Nature remains neutral with regard to jurisdictional claims in published maps and institutional affiliations. 